\title{
БИОЛОГИЧЕСКИ АКТИВНЫЕ СОЕДИНЕНИЯ НА ОСНОВЕ МОДИФИЦИРОВАННОЙ КСАНТАНОВОЙ КАМЕДИ
}

\author{
(C) О.Р. Ахмедов" ${ }^{* 1}$, Х.А. Сохибназарова ${ }^{2}$, Ш.А. Шомуротов ${ }^{1}$ \\ ${ }^{1}$ Институт биоорганической химии АН Республики Узбекистан, \\ ул. М. Улугбека 83, Ташкент, 100125 (Республика Узбекистан), \\ e-mail: ibchem@uzsci.net \\ ${ }^{2}$ Институт микробиологии АН Республики Узбекистан, ул. А. Кадыри, 7-Б, \\ Ташкент, 100128 (Республика Узбекистан), e-mail: info@microbio.uz
}

Проведена химическая модификация природного биополимера (ксантановой камеди) с помощью периодата натрия. Изменяя концентрацию окислителя, получили диальдегиды ксантановой камеди со степенью окисления 16,0-44,0 моль\%. Взаимодействием полученных диальдегидпроизводных полисахарида с гуанидином синтезированы новые водорастворимые азотсодержащие соединения. Структура и состав полученных соединений исследованы методом ИКспектроскопии и элементным анализом по содержанию азота. Вычислено количество гуанидина и степень замещения в синтезированных продуктах, которое составило $10,5-25,5$ и 31,0-85,0 моль\% соответственно.

Изучена биологическая активность полученных соединений в условиях in vitro в отношении патогенных микроорганизмов (Staphylococcus aureus, Staphylococcus epidermidis, Escherichia coli, Pseudomonas aeruginosa, Klebsiella) при концентрации препаратов 50 мг/мл. На основании результатов исследований установлено, что повышение степени замещения и количества гуанидина в полисахариде приводит к усилению антибактериального действия препаратов.

Полученные водорастворимые гуанидинсодержащие производные ксантановой камеди могут найти применение в качестве антибактериальных препаратов перорального и наружного применения.

Ключевые слова: ксантановая камедь, периодатное окисление, диальдегид производные, гуанидин, микробиологическое исследование, антибактериальное действие.

Работа выполнена при финансовой поддержке фонда фундаментальных исследований АН Республики Узбекистан (проект № T.1-16, 2016 г.).

\section{Введение}

Синтез новых производных полисахаридов, проявляющих биологическую активность, является одним из основных направлений в химии полимеров. Проведенные фармакологические и клинические исследования подтверждают перспективность применения физиологически активных соединений, полученных на основе природных полимеров в качестве замены лекарственным препаратам низкомолекулярной природы. В настоящее время получен широкий ассортимент изделий медицинского назначения и биологически активных соединений на основе таких полисахаридов, как целлюлоза, хитозан и декстран [1-4].

В последнее время большое внимание исследователей привлекает ксантановая камедь (КК), которая широко используется в качестве загустителей, стабилизаторов и эмульгаторов в пищевой, нефтяной и косметической промышленности, к тому же она является нетоксичным, биосовместимым и относительно недорогим природным полимером. В промышленном масштабе ксантановая камедь получается методом ферментации сахарозы или глюкозы бактериями Xanthomonas campestris. По химической природе КК

Ахмедов Олий Равщанович - младший научный сотрудник лаборатории «Химия полисахаридов», e-mail: oliy86@bk.ru Сохибназарова Хонсулув Абдувохидовна - младший научный сотрудник лаборатории «Генетика молочнокислых бактерий», e-mail: sumbul_nazar@mail.ru

Шомуротов Шавкат Абдуганиевич - старший научный сотрудник лаборатории «Химия полисахаридов», кандидат химических наук, e-mail: shsha@mail.ru представляет собой ионогенный полисахарид, главная цепь которого идентична целлюлозе и состоит из остатков $\beta$-D-глюкозы соединенных между собой посредством 1,4-гликозидной связи (рис. 1). Боковая часть ксантановой камеди содержит остатки D-глюкуроновой кислоты, связанные

\footnotetext{
* Автор, с которым следует вести переписку.
} 


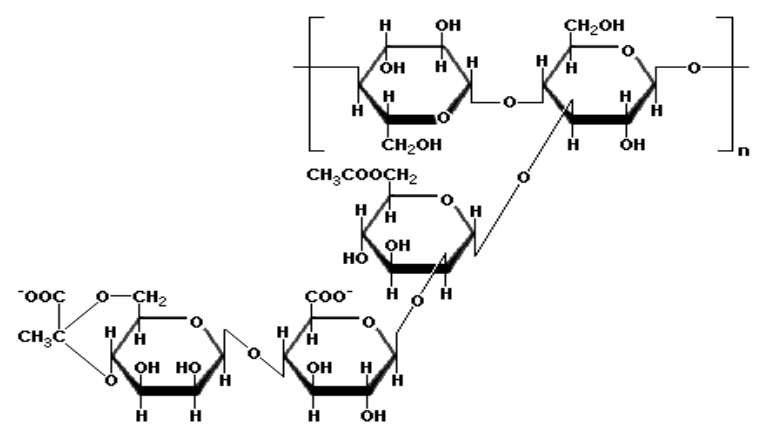

Рис. 1. Структурная формула ксантановой камеди с обеих сторон молекулами маннозы. В свою очередь, единицы D-маннозы содержат в структуре ацетильные и пируватные группы [5].

Благодаря свободным гидроксильным группам, имеющим вицинальное расположение, в работе [6] была проведена реакция периодатного окисления и получены диальдегидпроизводные ксантановой камеди. Такая модифицированная ксантановая камедь, может найти применение для получения новых биологически активных соединений, так как альдегидные группы, расположенные в структуре полисахарида, открывают возможности проведения реакций различного типа и введения в макромолекулу новых функциональных групп или лекарственных препаратов.

Исходя из вышеизложенного, в настоящей работе на основе диальдегидпроизводных ксантановой камеди синтезированы соединения, содержащие в структуре гуанидиновые группы, исследована их биологическая активность.

Для проведения исследований была использована ксантановая камедь (производитель СР Кelco (Шаньдун) Biological Co., Ltd) очищенная, имеющая следующие характеристики: вязкость $\geq 1400$, цвет белый с бежевым оттенком, $\mathrm{pH} 1 \%$ раствора $6,1-6,2$. В качестве нуклеофильного реагента использован гуанидин гидрокарбонат $-\left(\mathrm{H}_{2} \mathrm{~N}\right)_{2} \mathrm{C}=\mathrm{NH} \times 1 / 2 \mathrm{H}_{2} \mathrm{CO}_{3}$, марки х.ч.

\section{Экспериментальная часть}

Периодатное окисление ксантановой камеди. В стеклянном стакане 1 г КК залили 100 мл дистиллированной воды и оставили на 2 ч, затем добавили 100 мл ацетатного буферного раствора с $\mathrm{pH} 4,3$ и $0,2-$ 1,0 M раствора $\mathrm{NaJO}_{4}$ при мольном соотношении ксантановая камедь : $\mathrm{NaJO}_{4}=1,0: 1,0$. Процесс окисления продолжался 5 ч при температуре $25^{\circ} \mathrm{C}$. По окончании реакции периодатного окисления модифицированный полисахарид осаждали ацетоном. Образовавшиеся осадки промывали 75\%-ным этанолом до отрицательной реакции на ионы $\mathrm{JO}_{4}^{-}$и $\mathrm{JO}_{3}{ }^{-}$(контроль по реакции с раствором азотнокислого серебра). Полученные диальдегидпроизводные ксантановой камеди сушили в темноте под вакуумом над $\mathrm{P}_{2} \mathrm{O}_{5}$.Содержание альдегидных групп определили йодометрическим методом.

Получение гидрохлорид гуанидина ксантановой камеди. К растворам, содержащим 0,025 моль гуанидина гидрокарбоната, добавляли 0,01 моль окисленных производных ксантановой камеди, из расчета 1 моль диальдегидных звеньев на 2,5 моль $\left(\mathrm{H}_{2} \mathrm{~N}\right)_{2} \mathrm{C}=\mathrm{NH} \times 1 / 2 \quad \mathrm{H}_{2} \mathrm{CO}_{3}$ (нуклеофильного реагента брали в небольшом избытке) и перемешивали при температуре $25^{\circ} \mathrm{C}$ в течение 30 мин. Образовавшуюся азометиновую связь (-C=N-) восстанавливали с помощью боргидрида натрия. Реакция восстановления $-\mathrm{C}=\mathrm{N}-$ связи продолжалась 2 ч, боргидрида натрия брали в двукратном избытке по отношению к количеству альдегидных групп полисахарида. Затем в реакционные смеси по каплям добавляли 5\% раствор $\mathrm{HCl}$ и доводили $\mathrm{pH}$ среды до 6,0-6,1. Продукты реакции осаждали и промывали ацетоном. Образовавшиеся осадки растворяли в воде, очищали от примесей методом диализа в течение 48 ч и высушивали лиофилизацией.

ИК-спектры полученных соединений записаны на Фурье ИК-спектрометре Vector-22 в области длин волн 400-4000 $\mathrm{cm}^{-1}$ в таблетках $\mathrm{KBr}$ (3 мг образца / 300мг $\mathrm{KBr}$ ). Состав полученных гуанидинсодержащих производных ксантановой камеди изучали по содержанию азота. Количество азота определяли методом Кьельдаля. Степень замещения и количество гуанидина в конечных продуктах вычисляли по содержанию азота $[7,8]$. Антибактериальную активность гуанидинсодержащих производных ксантановой камеди изучали в условиях in vitro методом лунок в агаре.

\section{Обсуждение результатов}

В ИК-спектре ксантановой камеди (рис. 2) присутствовали полосы поглощения в области (см $\left.{ }^{-1}\right) 3360$

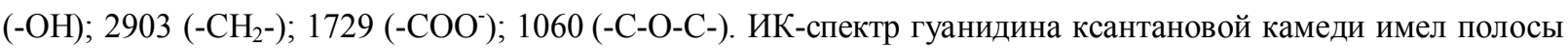
поглощения в области 1580 (-NH-) и $1667 \mathrm{~cm}^{-1}-\mathrm{C}=\mathrm{N}$ - связь гуанидинового фрагмента. 
Рис. 2. ИК-спектры ксантановой камеди (1) и гидрохлорид гуанидина ксантановой камеди (2)

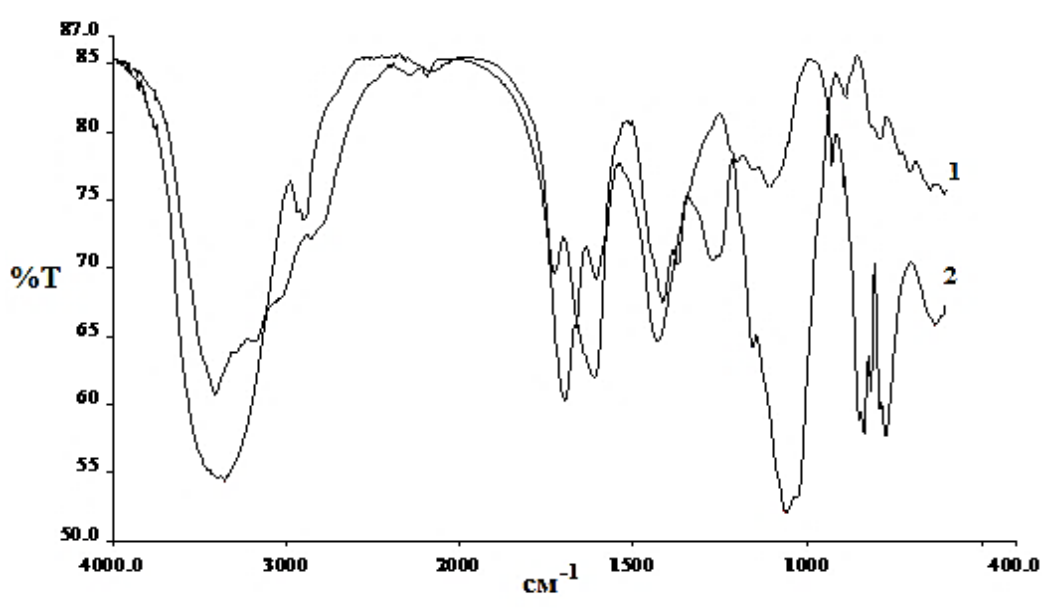

Как следует из таблицы 1 , с увеличением степени окисления ксантановой камеди повышается степень замещения и количество гуанидина в конечных продуктах. Данные, представленные в таблице, показывают, что при мольном соотношении $-\mathrm{CHO}:\left(\mathrm{H}_{2} \mathrm{~N}\right)_{2} \mathrm{C}=\mathrm{NH}=1,0: 2,5$ происходит практически полное взаимодействие альдегидных групп полисахарида с гуанидином.

Литературные источники свидетельствуют о том, что большинство производных гуанидина обладают широким спектром антибактериальной, фунгицидной и противогрибковой активности [7, 9, 10]. В связи с этим нами были проведены микробиологические исследования полученных гуанидинсодержащих производных ксантановой камеди в отношении некоторых патогенных бактерий (табл. 2).

Проведенные микробиологические исследования показали, что препарат №2, с количественным содержанием гуанидина 14,0\% и С $3=40,0$ моль\%, проявляет слабое антибактериальное действие в отношении Staphylococcus epidermidis, Pseudomonas aeruginosa и Klebsiella. С повышением количественного содержания гуанидина и степени замещения исследуемых соединений величина антибактериального действия начинает повышаться. Так, препарат №3 обладает умеренно выраженным действием в отношении Klebsiella. В отношении других микроорганизмов антибактериальное действие препарата №3 начинает увеличиваться. Наибольшая величина антибактериального действия наблюдается у препарата №5 (содержание гуанидина 25,5\% и С $3=85,0$ моль $\%)$, который обладает умеренно выраженным и выраженным действием в отношении Staphylococcus epidermidis,Pseudomonas aeruginosa и Klebsiella. В отношении Staphylococcus aureus и Escherichia coli антибактериальное действие исследованных соединений слабое или отсутствует.

Таблица 1. Состав продуктов взаимодействия окисленной ксантановой камеди с гуанидином при $25^{\circ} \mathrm{C}$ и соотношении $-\mathrm{CHO}:\left(\mathrm{H}_{2} \mathrm{~N}\right)_{2} \mathrm{C}=\mathrm{NH}=1,0: 2,5$

\begin{tabular}{c|c|c|c}
\hline $\begin{array}{c}\text { Степень окисления ксанта- } \\
\text { новой камеди, моль\% }\end{array}$ & Содержание азота, \% & $\begin{array}{c}\text { Степень замещения (С3) } \\
\text { моль\% }\end{array}$ & Количество гуанидина, \% \\
\hline 16,0 & 2,5 & 31,0 & 10,5 \\
21,0 & 3,3 & 40,0 & 14,0 \\
34,0 & 5,0 & 66,0 & 21,0 \\
38,0 & 5,5 & 74,0 & 23,0 \\
44,0 & 6,1 & 85,0 & 25,5 \\
\hline
\end{tabular}

Таблица 2. Чувствительность бактерий к гуанидинсодержащим производным ксантановой камеди, при концентрации препаратов 50 мг/мл

\begin{tabular}{l|c|c|c|c|c}
\hline \multicolumn{1}{|c|}{ Микроорганизмы } & $\begin{array}{c}\text { Staphylococcus } \\
\text { aureus }\end{array}$ & $\begin{array}{c}\text { Staphylococcus } \\
\text { epidermidis }\end{array}$ & Escherichia coli & $\begin{array}{c}\text { Pseudomonas } \\
\text { aeruginosa }\end{array}$ & Klebsiella \\
\hline $\begin{array}{l}\text { Зона задержки, } \\
\text { (мм) препарата № 2 }\end{array}$ & $8,0 \pm 0,2$ & $10,0 \pm 0,1$ & $9,0 \pm 0,1$ & $11,0 \pm 0,1$ & $13,0 \pm 0,2$ \\
$\begin{array}{l}\text { Зона задержки, } \\
\text { мм) препарата № 3 }\end{array}$ & $10,0 \pm 0,1$ & $12,0 \pm 0,2$ & $10,0 \pm 0,2$ & $13,0 \pm 0,1$ & $16,0 \pm 0,1$ \\
$\begin{array}{l}\text { Зона задержки, } \\
\text { (мм) препарата № 5 }\end{array}$ & $11,0 \pm 0,2$ & $15,0 \pm 0,1$ & $12,0 \pm 0,1$ & $15,0 \pm 0,1$ & $20,0 \pm 0,4$ \\
\hline
\end{tabular}

Примечание. Диаметры зон задержки роста меньше 10 мм - отсутствие антибактериальной активности; 10-15 мм слабая активность; 15-20 мм - умеренно выраженная активность; свыше 20 мм - выраженная. 
Зависимость эффекта антибактериальной активности полученных соединений от количества гуанидина и степени замещения связано с изменением плотности заряда макромолекулы [11, с.14], величина которой повышается с увеличением количества положительно заряженных групп в полисахариде. Вероятно, повышение плотности заряда макромолекулы определяет процесс электростатического взаимодействия исследуемых соединений с оболочкой микроорганизмов.

Таким образом, на основе диальдегидпроизводных ксантановой камеди получены соединения, содержащие в структуре гуанидиновые группы. Установлено, что величина антибактериального действия синтезированных соединений зависит от степени замещения и количества гуанидина.

\section{Bыводbl}

1. На основе диальдегидпроизводных ксантановой камеди получены водорастворимые гуанидинсодержащие соединения. Структура и состав полученных соединений определен методом ИК-спектроскопии и элементным анализом по содержанию азота.

2. Проведены микробиологические исследования синтезированных соединений в отношении патогенных бактерий. Установлено, что с повышением степени замещения и количества гуанидина в ксантановой камеди усиливается антибактериальное действие препаратов.

\section{Список литературы}

1. Геньш К.В., Базарнова Н.Г. Окисленная целлюлоза. Получение. Применение в медицине // Химия растительного сырья. 2013. №4. С. 13-20.

2. Yan J., Abdelgawad A., El-Naggar M.,Rojas O. Antibacterial activity of silver nanoparticles synthesized In-situ bysolution spraying onto cellulose // Carbohydrate Polymers.2016. Vol. 147. Pp. 500-508.

3. Вирник А.Д., Хомяков К.П., Скокова И.Ф. Декстран и его производные // Успехи химии. 1975. Т. XLIV. С. 1281-1307.

4. Хитин и хитозан. Получение, свойства и применение. М., 2002. 361 с.

5. Garcia-Ochoa F., Santos V., Casas J., Gomez A. Xanthan gum: production, recovery, and properties // Biotechnology Advances. 2000. Vol. 18. Pp. 549-579.

6. Guo J., Ge L., Li X., Mu Ch., Li D. Periodate oxidation of xanthan gum and its crosslinking effects on gelatin-based edible films // Food Hydrocolloids. 2014. Vol. 39. Pp. 243-250.

7. Liu K., Xu Y., Lin X., Chen L., Huang L., Cao Sh., Li J. Synergistic effects of guanidine-grafted CMC on enhancing antimicrobial activity and dry strength of paper // Carbohydrate Polymers. 2014. Vol. 110. Pp. 382-387.

8. Ding W., Zhao P., Li R. Removal of Zn (II) ions by dialdehyde 8-aminoquinoline starch from aqueous solution // Carbohydrate Polymers. 2011. Vol. 83. Pp. 802-807.

9. Патент 2435785 (РФ). Модифицированная целлюлоза, обладающая биоцидными свойствами и способ ее получения / М.Ю. Исрафилович, С.Ю. Хаширова, Э.Б. Мусаева, М.Х. Лигидов, С.Н. Александрович, 3.А. Тлупова. 2011.

10. Sahraro M., Yeganeh H., Sorayya M. Guanidine hydrochloride embedded polyurethanes as antimicrobial and absorptive wound dressing membranes with promising cytocompatibility // Materials Science and Engineering C. 2016. Vol. 59. Pp. 1025-1037.

11. Афиногенов Г.Е., Панарин Е.Ф. Антимикробные полимеры. СПб., 1993. 14 с.

Поступило в редакиию 15 января 20172. 
Akhmedov O.R..$^{{ }^{*}}$, Sohibnazarova KH.A. ${ }^{2}$, Shomurotov Sh.A. ${ }^{l}$ BIOLOGICALLY ACTIVE COMPOUNDS BASED ON MODIFIED XANTHAN GUM

${ }^{1}$ Institute of Bioorganic Chemistry of the Uzbek Academy of Sciences, M.Ulugbek st., 83, Tashkent, 100125

(Republic of Uzbekistan), e-mail: ibchem@uzsci.net

${ }^{2}$ Institute of microbiology of the Uzbek Academy of Sciences, A. Qodiriy st., Tashkent, 100128 (Republic of Uzbekistan), e-mail:info@microbio.uz

We carried out chemical modification of the natural biopolymer (xanthan gum) with sodium periodate. By varying the concentration of the oxidizing agent, dialdehydes of xanthan gum were obtained with degree of oxidation 16,0-44,0 mol\%. New soluble nitrogen compounds were synthesized by reacting obtained dialdehyde polysaccharide derivatives with guanidine. Structure and composition of the prepared compounds were investigated by IR spectroscopy and elemental analysis for nitrogen content. We calculated amount of guanidine and degree of substitution in the synthesized products, which amounted 31,0 $85,0 \mathrm{~mol} \%$ and $10,5-25,5 \%$ respectively.

Biological activity of the compounds in conditions in vitro was studied against pathogenic microorganisms (Staphylococcus aureus, Staphylococcus epidermidis, Escherichia coli, Pseudomonas aeruginosa, Klebsiella) at a concentration of $50 \mathrm{mg}$ $/ \mathrm{ml}$. Research results revealed that the increase in the degree of substitution and the amount of guanidine in the polysaccharide lead to increased antibacterial action of the agents. Obtained water-soluble guanidine derivatives containing xanthan gum may be used as antibacterial agents for oral and external applications. terial effect.

Keywords: xanthan gum, periodate oxidation, dialdehyde derivatives, guanidine, microbiological examination, antibac-

\section{References}

1. Gensh K.V., Bazarnova N.G. Khimiia rastitelnogo syria, 2006, no. 2, pp. 25-28. (in Russ.).

2. Yan J., Abdelgawad A., El-Naggar M., Rojas O. Carbohydrate Polymers, 2016, vol. 147, pp. 500-508.

3. Virnik A.D., Khomiakov K.P., Skokova I.F. Uspekhi khimii, 1975, vol. XLIV, pp. 1281-1307. (in Russ.).

4. Khitin i khitozan. Poluchenie, svoistva i primenenie. [Chitin and Chitosan. Preparation, Properties and Applications]. Moscow, 2002, 361 p. (in Russ.).

5. Garcia-Ochoa F., Santos V., Casas J., Gomez A. Biotechnology Advances, 2000, vol. 18, pp. 549-579.

6. Guo J., Ge L., Li X., Mu Ch., Li D. Food Hydrocolloids, 2014, vol. 39, pp. 243-250.

7. Liu K., Xu Y., Lin X., Chen L., Huang L., Cao Sh., Li J. Carbohydrate Polymers, 2014, vol. 110, pp. 382-387.

8. $\quad$ Ding W., Zhao P., Li R. Carbohydrate Polymers, 2011, vol. 83, pp. 802-807.

9. Patent 2435785 (RU). 2011. (in Russ.).

10. Sahraro M., Yeganeh H., Sorayya M. Materials Science and Engineering C, 2016, vol. 59, pp. 1025-1037.

11. Afinogenov G.E., Panarin E.F. Antimikrobnye polimery. [Antimicrobial polymers]. St. Petersburg, 1993, 14 p. (in Russ.).

Received January 15, 2017

Revised January 31, 2017

\footnotetext{
${ }^{*}$ Corresponding author.
} 
